\title{
PERFIL RADICULAR DA FIGUEIRA SOB EFEITO DE NÍVEIS DE ADUBAÇÃO ORGÂNICA ${ }^{1}$
}

\author{
SARITALEONEL ${ }^{2}$, ERVAL RAFAEL DAMATTO JUNIOR ${ }^{3}$
}

RESUMO - O presente trabalho objetivou avaliar a distribuição do sistema radicular da figueira 'Roxo de Valinhos' em função da aplicação de níveis de adubação orgânica durante quatro anos. A cultura foi conduzida em Botucatu-SP, no espaçamento de 3 x 2 m, num solo classificado como Nitossolo Vermelho. Os tratamentos corresponderam a níveis crescentes de adubação orgânica com esterco de curral, conforme a recomendação de N para a cultura: testemunha (sem adubação), $25 \% ; 50 \% ; 75 \% ; 100 \% ; 125 \%$ e 150 $\%$ da dose recomendada. A avaliação da distribuição do sistema radicular foi realizada 4 anos após a instalação da cultura, sendo que, de cada planta, foram retiradas quatro amostras a $0-40 \mathrm{~cm}$ de distância do tronco, na profundidade de 0-40 cm. As amostras foram submetidas à lavagem e secagem em estufa $\left(65^{\circ} \mathrm{C}\right)$, para posteriormente avaliar a massa seca das raízes. O sistema radicular mostrouse mais desenvolvido horizontalmente do que na vertical. O menor peso de raízes foi obtido sem esterco (43,3 g), e o maior, com 150 $\%$ da dose de $\mathrm{N}$ recomendada $(177,7 \mathrm{~g})$.

Termos para indexação: Ficus carica L., raízes, esterco.

\section{ROOT DISTRIBUTION OF FIG TREES CULTIVATED WITH ORGANIC MANURE}

\begin{abstract}
The research had as purpose to evaluate the root system distribution of 'Purple of Valinhos' fig plants cultivated with manure levels, during four years. The fig orchard was planted in Botucatu-SP, at a Red Nitossolo soil with the plants designed at 3 $\mathrm{m}$ between lines and $2 \mathrm{~m}$ between plants. The treatments were constituted by increasing organic manure levels with cattle manure, according to the recommended nitrogen level for the trees: control (without manure), $25 \%, 50 \%, 75 \%, 100 \%, 125 \%$ and $150 \%$ of level manure recommended. The evaluation of root system distribution were made four years after the orchard installation. From each plant were taken four samples at 0-40 cm distance of the stem, in the depth of 0-40 cm. After, the samples were washed and dried $\left(65^{\circ} \mathrm{C}\right)$ for post-evaluation of the dry weight, depth and distance of the roots. It was observed that the root development was higher in the horizontal position when compared with the vertical. The bigger root weight was obtained with the application of $150 \%$ of $\mathrm{N}$ level recommended and the smaller root weight was observed without manure $(43,3 \mathrm{~g})$.
\end{abstract}

Index terms: Ficus carica L., roots, manure.

A figueira (Ficus carica L.) foi introduzida no Brasil a partir de 1532, mas somente a partir do século passado, com a introdução de grande número de variedades, a cultura começou a se expandir, sendo que sua importância econômica no Estado de São Paulo se deu nos últimos sessenta anos (Amaro, 1972). Conforme dados do Ministério da Agricultura (2005), a área colhida com a cultura da figueira no Brasil, em 2003, foi de 3.130 ha, com produção de 25.586 toneladas, alcançando produtividade média de $8,2 \mathrm{t} / \mathrm{ha}$.

Os Estados do Rio Grande do Sul e São Paulo são os maiores produtores, sendo que São Paulo apresenta cerca de 840 mil pés de figueira em produção, concentrada na região de Campinas, com mais de 600 mil pés (Almeida \& Silveira, 1997; INFORMAÇÕES ESTATÍSTICAS DAAGRICULTURA, 2000; IBGE, 2002). No entanto, na última década, a ficicultura paulista tem enfrentado um desestímulo ao cultivo nas tradicionais regiões produtoras (Campinas e Valinhos) devido a questões associadas ao custo de produção e ao fator terra, que passaram a exercer pressão sobre o custo total, devido à especulação imobiliária.

O conhecimento do correto manejo do pomar, apropriado à região produtora, bem como aspectos de adubação e nutrição mineral figuram como informações relevantes de sucesso, não apenas nas áreas novas de cultivo, como também nas já existentes.

As exigências nutricionais para a cultura da figueira são pouco conhecidas, sendo que os relatos disponíveis versam sobre o uso da adubação orgânica como prática favorável, tanto no desenvolvimento como na produção das figueiras. De acordo com Penteado (1986), fatores de nutrição mineral equilibrados e satisfatórios durante a fase de formação de plantas garantem boas safras na fase produtiva das mesmas. Segundo Almeida \& Silveira (1997), em observações práticas, foi demonstrado que solos areno-argilosos, bem drenados e com bom teor de matéria orgânica são os que apresentam melhores características agronômicas para o bom desenvolvimento da figueira.

O comportamento da figueira, no que se refere às exigências de solo e nutrição, exige conhecimentos da distribuição do sistema radicular. Conforme Rigitano (1955), nesse aspecto, a planta não apresenta muitas particularizações, como a maioria das espécies frutíferas, visto que não se utiliza porta-enxerto, sendo a propagação exclusivamente por estaquia. Quanto à

(Trabalho 068-2006). Trabalho financiado pela FAPESP (Processo 01/04398-1).Recebido em 22-05-2006. Aceito para publicação em 18-12-2006. ${ }^{2}$ Prof. Dr. do Departamento de Produção Vegetal - Faculdade de Ciências Agronômicas - UNESP, Botucatu-SP. E-mail: sarinel@fca.unesp.br.

${ }^{3}$ Eng. Agr. Doutorando da Faculdade de Ciências Agronômicas - UNESP, Botucatu-SP. E-mail: ervaljr@fca.unesp.br. Bolsista Fapesp. 
existência de cultivares, reporta-se apenas ao uso do 'Roxo de Valinhos'. Para Condit (1947), embora a distribuição das raízes da planta se situe mais próxima do tronco, em condições favoráveis, pode alcançar grandes distâncias, sendo que, na Califórnia, encontraram-se raízes ultrapassando seis metros de profundidade.

O presente trabalho teve como objetivo avaliar a distribuição do sistema radicular da figueira, submetida a diferentes níveis de adubação orgânica, após quatro anos de experimentação.

O trabalho foi conduzido no pomar do Departamento de Produção Vegetal - Horticultura da Faculdade de Ciências Agronômicas/UNESP, em Botucatu-SP (22 ${ }^{\circ} 52^{\prime}$ S, $48^{\circ} 26^{\prime} \mathrm{W}$ e altitude $786 \mathrm{~m}$ ), com clima temperado quente (mesotérmico), com chuvas no verão e seca no inverno (Cwa - Koppen), e temperatura média mais quente superior a $22^{\circ} \mathrm{C}$ (Cunha et al., 1999). O solo da área foi classificado como Nitossolo Vermelho, segundo os critérios da Embrapa (1999).

A área do experimento foi preparada dois meses antes do plantio, realizando aração, seguida de calagem em área total, conforme a análise de solo, objetivando elevar a saturação de bases a $70 \%$ (Raij et al., 1997), utilizando calcário dolomítico, e finalmente realizou-se a gradagem. O plantio das mudas de figueira no campo foi realizado em setembro de 2001, com mudas de figueira 'Roxo de Valinhos', adotando o espaçamento de $3 \mathrm{~m}$ entre linhas e $2 \mathrm{~m}$ entre plantas ( $6 \mathrm{~m}^{2} /$ planta), representando uma densidade de 1.660 plantas/ha. O plantio foi feito seguindo as curvas de nível do terreno, para facilidade nos tratos mecanizados, e as dimensões das covas foram de $60 \times 60 \times 60 \mathrm{~cm}$, nas quais foram adicionados 20 litros de esterco de curral, $1 \mathrm{~kg}$ de calcário e $1 \mathrm{~kg}$ de termofosfato magnesiano contendo boro e zinco. As plantas foram podadas no mês de julho dos anos de 2002 a 2005, com a finalidade de adquirirem a conformação de 12 ramos produtivos, que é considerada a mais recomendada para a cultura, podendo suas produções, a partir daí, serem consideradas de nível comercial (Rigitano, 1964; Penteado \& Franco, 1997).

Os tratamentos, correspondentes aos níveis de adubação orgânica com esterco de curral curtido, foram ministrados nos meses de agosto e setembro dos anos de 2002 a 2004, com metade da dose em cada mês, empregando-se quantidades crescentes: testemunha (sem adubação), $25 \% ; 50 \% ; 75 \% ; 100 \% ; 125 \%$ e $150 \%$ da dose recomendada, sendo essas doses calculadas de acordo com o teor de nitrogênio presente no esterco, conforme Raij et al. (1997). As quantidades de nitrogênio e de esterco aplicados em cada tratamento se encontram na Tabela 1. Na Tabela 2, são apresentados os teores de nutrientes presentes nos estercos empregados para as adubações das figueiras. Além da adubação orgânica, realizou-se, em todos os tratamentos, a adubação complementar com termofosfato, aplicando-se $60 \mathrm{~g}$ de $\mathrm{P}_{2} \mathrm{O}_{5}$ no $1^{\circ}$ e $2^{\circ}$ anos e $100 \mathrm{~g}$ de $\mathrm{P}_{2} \mathrm{O}_{5}$ no $3^{\circ}$ ano.

$\mathrm{O}$ esterco foi aplicado ao redor das plantas, inicialmente num raio de $30 \mathrm{~cm}$ a partir do tronco da planta. Nas adubações seguintes, essa distância foi aumentando, até atingir a área total da projeção da copa, acompanhando o crescimento do sistema radicular. Após a aplicação do esterco no solo, realizou-se uma incorporação superficial (aproximadamente a $5 \mathrm{~cm}$ de profundidade) com auxílio de enxada.
TABELA 1 - Níveis de nitrogênio empregados na forma de esterco de curral curtido nas adubações anuais (agosto/2002 a agosto/2004). BotucatuSP,UNESP, 2006.

\begin{tabular}{ccccccc}
\hline \% da dose de $\mathrm{N}$ & \multicolumn{3}{c}{ Níveis de N (g/planta) } & \multicolumn{3}{c}{ Doses de esterco (kg/planta) } \\
\cline { 2 - 7 } recomendada & $1^{\circ}$ ano & $2^{\circ}$ ano & $3^{\circ}$ ano & $1^{\circ}$ ano & $2^{\circ}$ ano & $3^{\circ}$ ano \\
\hline $0 \%$ & 0 & 0 & 0 & 0 & 0 & 0 \\
$25 \%$ & 10 & 20 & 30 & 0,8 & 0,82 & 1,9 \\
$50 \%$ & 20 & 40 & 60 & 1,6 & 1,64 & 3,8 \\
$75 \%$ & 30 & 60 & 90 & 2,4 & 2,46 & 5,7 \\
$100 \%$ & 40 & 80 & 120 & 3,2 & 3,28 & 7,6 \\
$125 \%$ & 50 & 100 & 150 & 4,0 & 4,10 & 9,5 \\
$150 \%$ & 60 & 120 & 180 & 4,8 & 4,92 & 11,4 \\
\hline
\end{tabular}

TABELA 2 - Análise química dos estercos de curral curtidos utilizados para as adubações das figueiras $\left(1^{\mathrm{a}}\right.$ : agosto/2002; $2^{\text {a. }}$ junho/2003; $3^{\text {a }}$ : julho/2004.). Botucatu-SP, UNESP, 2006.

\begin{tabular}{|c|c|c|c|c|c|c|c|c|c|}
\hline \multirow[b]{2}{*}{ Amostra } & \multicolumn{9}{|c|}{ Resultado em porcentagem na matéria seca } \\
\hline & $\mathbf{N}$ & $\mathbf{P}_{2} \mathrm{O}_{5}$ & $\mathrm{~K}_{2} \mathrm{O}$ & Umidade & MO & $\mathbf{C}$ & Ca & Mg & $\mathbf{S}$ \\
\hline $1^{\mathrm{a}}$ & 1,26 & 1,52 & 1,68 & 41,00 & 43,00 & 23,89 & 1,50 & 0,50 & 0,18 \\
\hline $2^{\mathrm{a}}$ & 2,45 & 2,14 & 1,55 & 37,00 & 41,00 & 23,00 & 1,14 & 0,45 & 0,35 \\
\hline \multirow[t]{2}{*}{$3^{\mathrm{a}}$} & 1,58 & 0,94 & 0,92 & 48,32 & 39,00 & 21,70 & 1,29 & 0,84 & 0,21 \\
\hline & & \multicolumn{8}{|c|}{ Resultado em $\mathrm{mg} / \mathrm{kg}$ na matéria seca } \\
\hline \multicolumn{2}{|c|}{ Amostra } & $\mathbf{F e}$ & $\mathbf{C u}$ & Mn & \multicolumn{2}{|c|}{$\mathbf{N a}$} & $\mathbf{Z n}$ & pH & $\mathbf{C} / \mathbf{N}$ \\
\hline \multicolumn{2}{|l|}{$1^{\mathrm{a}}$} & 11300 & 120 & 146 & \multicolumn{2}{|c|}{ N/D } & 190 & 7,6 & $19 / 1$ \\
\hline \multicolumn{2}{|l|}{$2^{\mathrm{a}}$} & 7950 & 302 & 308 & \multicolumn{2}{|c|}{1860} & 300 & 7,20 & 9/1 \\
\hline \multicolumn{2}{|l|}{$3^{\mathrm{a}}$} & 14300 & 6 & 5250 & 58 & & 286 & 14,00 & $14 / 1$ \\
\hline
\end{tabular}

Fonte: Laboratório de Análises de Fertilizantes e Corretivos. DRN-FCA.

TABELA 3 - Distribuição do sistema radicular de figueira em função de níveis de adubação orgânica. Botucatu-SP- UNESP, 2006.

\begin{tabular}{cccccc}
\hline $\begin{array}{c}\text { \% da dose de N } \\
\text { recomendada }\end{array}$ & $\begin{array}{c}\text { Massa seca } \\
\text { Total } \\
\left(\mathrm{g} \cdot \mathrm{dm}^{-3}\right)\end{array}$ & $\begin{array}{c}\text { Profund. } \\
0-40 \mathrm{~cm}\left(\mathrm{~g} \cdot \mathrm{dm}^{-3}\right)\end{array}$ & $\begin{array}{c}\text { Profund. } \\
0-40 \mathrm{~cm}(\%)\end{array}$ & $\begin{array}{c}\text { Distância } \\
0-40 \mathrm{~cm}\left(\mathrm{~g} \cdot \mathrm{dm}^{-3}\right)\end{array}$ & $\begin{array}{c}\text { Distância } \\
0-40 \mathrm{~cm} \\
(\%)\end{array}$ \\
\hline $0 \%$ & 43,3 & 12,1 & 27,9 & 31,2 & 72,1 \\
$25 \%$ & 58,9 & 28,1 & 47,7 & 30,8 & 52,3 \\
$50 \%$ & 56,9 & 13,7 & 6,3 & 53,2 & 93,7 \\
$75 \%$ & 63,5 & 24,4 & 38,4 & 39,1 & 61,6 \\
$100 \%$ & 118,7 & 22,1 & 18,6 & 96,6 & 81,4 \\
$125 \%$ & 110,9 & 15,3 & 13,2 & 98,9 & 86,8 \\
$150 \%$ & 177,7 & 37,6 & 21,2 & 140,1 & 78,8 \\
\hline Médias & 89,9 & 21,9 & - & 69,9 & - \\
\hline C.V. $(\%)$ & 14,0 & 12,8 & - & 14,1 & - \\
\hline F & $43,76^{* *}$ & $31,45^{* *}$ & - & $50,63^{* *}$ & - \\
\hline
\end{tabular}

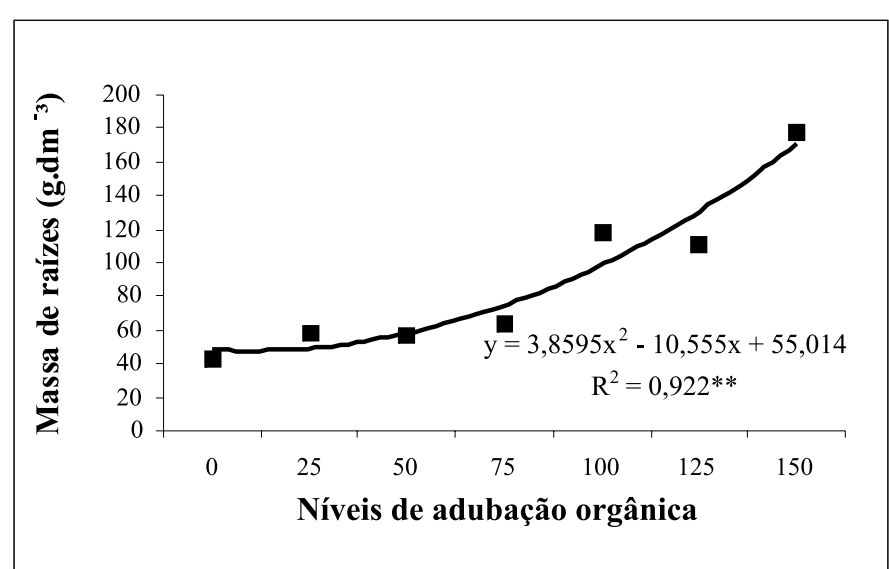

FIGURA 1 - Massa seca total do sistema radicular de figueira em função de níveis de adubação orgânica. BotucatuSP, UNESP, 2006. 


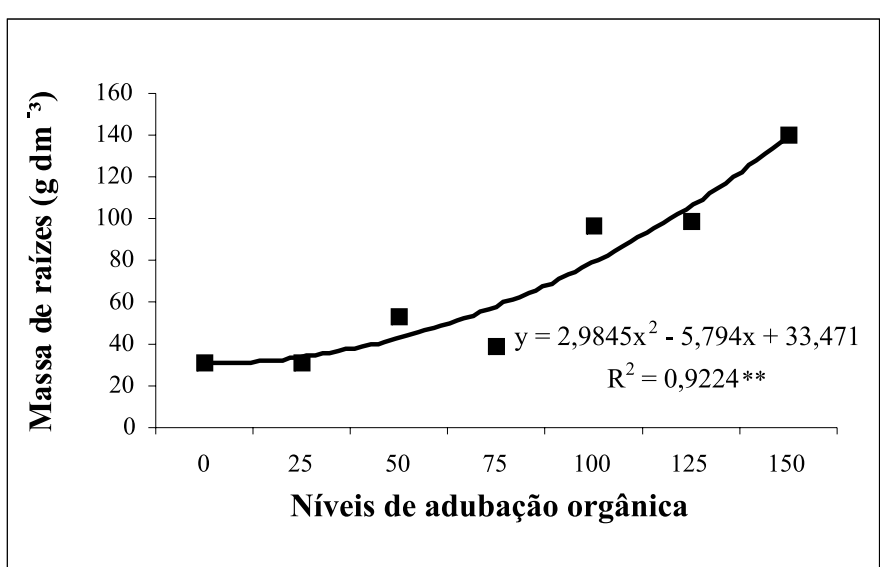

FIGURA 2 - Distância do sistema radicular de figueira $(0-40 \mathrm{~cm})$ avaliada pela massa de raízes, em função de níveis de adubação orgânica. Botucatu-SP, UNESP, 2006.

A avaliação da distribuição do sistema radicular foi realizada 4 anos após a instalação da cultura. De cada planta, foram retiradas quatro amostras a $0-40 \mathrm{~cm}$ de distância do tronco, na profundidade de $0-40 \mathrm{~cm}$. A seguir, as amostras foram submetidas à lavagem, com auxílio de peneira para a eliminação da terra aderida às raízes, e colocadas em estufa com circulação de ar forçado a $65^{\circ} \mathrm{C}$, para secagem. As características avaliadas foram massa seca, profundidade e distância de raízes, expressos em $\mathrm{g} \mathrm{dm}^{-3}$ de solo e em porcentagem.

Utilizou-se o delineamento experimental inteiramente casualizado, com 4 repetições, sendo cada parcela experimental representada por 1 planta. Realizou-se a análise de variância e, quando houve significância, a análise de regressão.

O sistema radicular das plantas de figueira em formação difere entre os tratamentos quanto ao peso total do sistema radicular (Tabela 3 e Figuras 1 e 2), na profundidade e distância de $0-40 \mathrm{~cm}$, isto porque, apesar de as avaliações terem sido efetuadas em duas profundidades e distâncias do caule, optouse por apresentar o somatório dos resultados para possibilitar a comparação estatística dos tratamentos avaliados. O tratamentotestemunha, no qual não houve aplicação de nitrogênio na forma de esterco de curral curtido, apresentou a menor massa total de raízes ( $43,3 \mathrm{~g}$ ), enquanto, com $150 \%$ da dose recomendada, foi observada a maior massa total de raízes $(177,7 \mathrm{~g})$. Segundo CAMPO - DALL'ORTO et al. (1996), o principal efeito da adubação orgânica é na melhoria das propriedades físicas e biológicas do solo, permitindo melhor aeração, retenção de água e atividade microbiana. Somado a isso, de acordo com KIEHL (1985), o esterco de curral, tendo como base a matéria seca, apresenta em média, 1,7\% N; 0,7 \% P2O5; 2,7 \% $\mathrm{K}_{2} \mathrm{O} ; 1,2 \% \mathrm{Ca}$; 0,61\% Mg e 31 ppm Cu; 4.106 ppm Fe; 510 ppm Mn; 64 ppm Zn e relação $\mathrm{C} / \mathrm{N}$ de $32 / 1$, fornecendo elementos nutrientes ao solo, ainda que em quantidades pequenas. Nas condições de solo com alto teor de argila em que foi realizado o presente trabalho, as referidas propriedades da matéria orgânica adicionada permitiram as inferências sobre o melhor desenvolvimento do sistema radicular da figueira.

Os resultados avaliados na profundidade e distância (esquerda e direita) de $0-40 \mathrm{~cm}$ do caule da planta evidenciaram que o sistema radicular é mais desenvolvido horizontalmente do que na vertical, o que é uma característica já conhecida das plantas que se propagam através da estaquia. Segundo Almeida e Silveira (1997) e Simão (1998), o método de propagação da figueira através da estaquia exerce influência na disposição do sistema radicular, tornando-o mais fibroso e superficial. Também Rigitano (1955) e Maiorano (1997) reportam que as raízes de figueira são fibrosas, em geral pouco profundas, sendo que essas plantas exigem práticas de manejo adequadas quanto aos aspectos de suprimento de água e fornecimento de adubos.

Venega \& Corrêa (1998), observando a distribuição das raízes de figueira, reportaram que cerca de $50 \%$ das raízes estavam distribuídas nos primeiros $0,15 \mathrm{~m}$ de profundidade de solo. $\mathrm{Na}$ distribuição horizontal, cerca de $50 \%$ das raízes estavam até 0,15 $\mathrm{m}$ de distância do tronco. Tais resultados vêem corroborar os obtidos no presente trabalho, onde se observou que grande parte das raízes de figueira se concentraram numa faixa de 0-40 $\mathrm{cm}$ de profundidade e distância do caule. Neste trabalho também foi possível evidenciar que as doses crescentes de esterco de curral aplicadas promoveram incrementos quadráticos no peso da matéria seca das raízes (Figura 1), permitindo inferir sobre a utilização dessa prática para melhorar a distribuição do sistema radicular no perfil do solo.

A adição de matéria orgânica ao solo melhora a distribuição do sistema radicular de plantas de figueira em formação. A distribuição do sistema radicular é maior no sentido horizontal de distância do caule.

\section{REFERÊNCIAS}

ALMEIDA, M. M. de; SILVEIRA, E. T. da. Tratos culturais na cultura da figueira no sudoeste de Minas Gerais. Informe Agropecuário, Belo Horizonte, v.18, n.188, p.27-33, 1997.

AMARO, A.A. Uma análise da comercialização de figo em São Paulo. Piracicaba, 1972. 71 f. Tese (Doutorado em Economia Aplicada) - Escola Superior de Agricultura “Luiz de Queiroz", Universidade de São Paulo, Piracicaba, 1972.

CAMPO - DALL'ORTO, F.A. et al. Frutas de clima temperado: II. Figo, maçã, marmelo, pêra e pêssego em pomar compacto. In: RAIJ, B. van et al. (Ed.). Recomendações de adubação e calagem para o Estado de São Paulo. 2. ed. Campinas: Instituto Agronômico Fundação IAC, 1996. p.39-140.

CONDIT, I.J. The fig. Massachusetts: Chronica Botanica, 1947. $222 \mathrm{p}$.

CUNHA, A.R.; KLOSOWSKI, E.S.; GALVANI, E.; SCOBEDO, J.F.; MARTINS, D. Classificação climática para o município de Botucatu-SP, segundo Koppen. In: SIMPÓSIO EM ENERGIA NAAGRICULTURA, 1., 1999, Botucatu. Anais... Botucatu: Faculdade de Ciências Agronômicas, Universidade Estadual Paulista, 1999. p.487-491.

EMBRAPA. Centro Nacional de Pesquisa de Solos. Sistema brasileiro de classificação de solos. Rio de Janeiro, 1999. 412 p.

INFORMAÇÕES ESTATÍSTICAS DAAGRICULTURA. Anuário IEA, São Paulo, v.11, n.1, 236 p, 2000.

IBGE - INSTITUTO BRASILEIRO DE GEOGRAFIA E ESTATÍSTICA. Disponível em: 〈http://www.ibge.gov.br〉. Acesso em: 05 maio 2002. 
KIEHL, E.J. Fertilizantes orgânicos. São Paulo: Agronômica Ceres. 1985, 492p.

MAIORANO, J.A. et al. Botânica e caracterização de cultivares de figueira. Informe Agropecuário, Belo Horizonte, v.18, n.188, p.22-24, 1997.

MINISTÉRIO DA AGRICULTURA, PECUÁRIA E ABASTECIMENTO. Estatísticas. Disponível em: <http:// www.agricultura.gov.br>. Acesso em: 10 fev. 2005.

PENTEADO, S.R.; FRANCO, J.A.M. Figo (Ficus carica L.). Manual técnico das culturas. Campinas: SAA/CATI/DCT, 1997.p. 127-139.

PENTEADO, S. R. Fruticultura de clima temperado em São Paulo. Campinas: Fundação Cargill, 1986. p.115-129.

RAIJ, B. van; CANTARELLA, H.; QUAGGIO, J.A.; FURLANI, A.M.C. (Ed). Recomendações de adubação e calagem para o Estado de São Paulo. 2.ed. rev. e atual. Campinas: Instituto Agronômico/Fundação IAC, 1997. 285p. (Boletim Técnico, 100 ).

RIGITANO, O. A figueira cultivada no Estado de São Paulo. 1955. 59 f. Tese (Doutorado em Fitotecnia/Fruticultura) - Escola Superior de Agricultura "Luiz de Queiroz", Universidade de São Paulo, Piracicaba, 1955.

RIGITANO, O. Instruções para a cultura da figueira. Campinas: SAA/IAC, 1964.30p. (Boletim Técnico, 146).

SIMÃO, S. Tratado de fruticultura. Piracicaba: FEALQ, 1998. $760 \mathrm{p}$.

VENEGA, M.F.; CORRÊA, L. de S. Distribuição do sistema radicular da figueira (Ficus carica L.) cultivada num Latossolo Vermelho Escuro, na região de Selvíria-MS. Cultura Agronômica, Ilha Solteira, v.7, n.1, p.65-72, 1998. 